UDC 61

\title{
THE QUALITY OF TRAUMA CARE IN EMERGENCY DEPARTMENT OF SAIFUL ANWAR GENERAL HOSPITAL, MALANG, INDONESIA
}

\author{
Haedar Ali*, Dradjat Respati S. \\ Department of Emergency Medicine, Faculty of Medicine, University of Brawijaya, Indonesia \\ *E-mail: alihaedar.fk@ub.ac.id
}

\begin{abstract}
Trauma registry can provide necessary information for monitoring and modifying trauma care. One-year trauma patients' data from medical record meeting subject criteria were retrospectively included. Calculation of Trauma and Injury Severity Scoring (TRISS) probability of survival requires data of the patient's age, mechanism of injury, Injury Severity Score (ISS), and Revised Trauma Score (RTS). A 1594 (12.69\%) out of 12562 patients had probability of survival $(\mathrm{Ps})$ of less $50 \%(\mathrm{Ps}<0.5)$. The remaining 10968 patients $(87.31)$ had more than $50 \%$ chance of survival (Ps>0.5). There were 1471 (92.28\%) unexpected survivals, while there were $10745(97.97 \%)$ expected survivals. The expected deaths in our study population were $123(7.72 \%)$, however there were $223(2.03 \%)$ unexpected deaths. Z statistic was calculated as -0.29 , with a $W$ score of 9.93 . The actual mortality was lower than what was predicted. Both $\mathrm{Z}$ score and $\mathrm{W}$ score reflect good performance in the management of major injury patients.
\end{abstract}

\section{KEY WORDS}

MTOS, quality of trauma score, TRISS, W score, Z score.

Worldwide, injury is the major public health problem. ${ }^{1}$ And the World Health Organization predicts that by year 2020, trauma will be the leading cause of years of life lost for both developed and the developing nations. ${ }^{2}$ At the Emergency Department (ED) of Saiful Anwar General Hospital (RSSA) Malang - Indonesia, according to the data in 2000, trauma counted for $40.7 \%$ out of total annual attendance, and the mortality rate was $1.46 \%$. Furthermore, in that period approximately 10 persons per day admitted to the hospital were classified as having traumatic causes. And it tended to be worse until present days. ${ }^{3,4}$

Trauma is a significant health problem and death after potentially salvageable injuries has been reported. It is attributed to inadequate pre-hospital care, resuscitation, and definitive care. ${ }^{2}$ However, very few objective data on injury severity, outcome, and process of trauma care have been published from RSSA. ${ }^{3,4}$ The lack of trauma related data is a major impediment in recognition of deficiencies in care. Trauma database in the form of a registry can provide necessary information for monitoring and modifying trauma care. These databases in ED of RSSA are used for objective comparison based on Trauma and Injury Severity Scoring (TRISS) method. ${ }^{2}$ We report the outcome of managing trauma based on registry data over a one-year period from 1 May 2004 to 30 April 2005. The outcomes were compared to norms established in North America based on data from Major Trauma Outcome Study (MTOS). ${ }^{1,2}$

TRISS system is based on a combination of patient age, mechanism of injury, Revised Trauma Score (RTS), and Injury Severity Score (ISS). ${ }^{1}$ Developed in the 1980 s to improve the prediction of patient outcome following trauma through the use of physiological and anatomical criteria, implementation of TRISS is widespread. TRISS is used for a number of purposes including quantifying the severity of injury of a patient population, calculating the probability of survival of patients for identification of cases for peer review, and comparing the death or survival rates of different populations/hospitals. ${ }^{1,2}$ Over the past 20 years, a number of changes have occurred. The care of trauma patients has improved, advanced statistical techniques have been developed, and alternative outcome measurement tools have been devised. ${ }^{5}$ Despite these advancements and the identification of numerous 
limitations of TRISS, it continues to be the most commonly used tool for judging hospital performance and monitoring trauma death rates. ${ }^{5}$

Considerable research has been conducted in an attempt to predict the probability of survival of trauma patients using MTOS database.

\section{METHODS OF RESEARCH}

All trauma patients admitted from 1 May 2004 to 30 April 2005 meeting subject criteria (table 1) including patients transferred from another hospital, patients admitted to an intensive care unit, and all patient dying in the emergency room were included in the study. The patients assessed in the ED, and the data measured while patients were in the ED. ${ }^{6}$

Table 1 - Subject criteria

\begin{tabular}{|ll|}
\hline 1. & Patients admitted to ED of RSSA from 1 May 2004 to 30 April 2005 \\
\hline 2. & Patient who was evaluated in ED of RSSA, and assessed as having trauma \\
\hline 3. & Patient who had ISS score $\geq 1$ \\
\hline 4. & $\begin{array}{l}\text { Patient who has complete medical record; including sex, age, ISS score, GCS, blood pressure, respiratory } \\
\text { rate, injury type, outcome condition }\end{array}$ \\
\hline 5. & Intoxication and burn patients are excluded \\
\hline
\end{tabular}

This research was designed with retrospective cases. The data had been taken from medical record database in ED RSSA, in order to identify outcome quality of trauma patients by using TRISS system. Calculation of TRISS probability of survival requires data of the patient's age, mechanism of injury (penetrating and blunt), ISS, and RTS. ${ }^{5}$

RTS is comprised of the systolic blood pressure, respiratory rate, and the Glasgow Coma Scale (GCS) score. ${ }^{7,8}$ Each of these factors is a measurement of the physiological state of the injured patient. ${ }^{7,8}$ A score is allocated for each of the three components of the RTS and weighted according to coefficients derived from MTOS database ${ }^{7,8}$ Higher values are associated with better prognoses. ${ }^{7,8,9}$

ISS is a summary score for multiple traumatic injuries. ISS takes values from 1 to $75^{5,7}$ Any patient with an Abbreviated Injury Scale (AIS) of 6 is assigned and ISS of 75 . Otherwise ISS is calculated by summing the squares of the three highest AIS scores for injuries to different body regions. ${ }^{5,7}$ ISS correlates with mortality, but has documented limitations. ${ }^{5,7}$ It only considers the highest AIS score from anybody region, and it considers injuries with equal AIS scores to be of equal severity, regardless of body region. ${ }^{8,9}$ Nonetheless, ISS remains the most frequently used summary measure of severity of anatomic injuries. ${ }^{8,10}$

For the purposes of TRISS calculation, the mechanism of injury is separated into two categories: penetrating and blunt injuries. ${ }^{11}$ The majority of cases are classified as blunt trauma, and this broad categorization includes different mechanisms such as motor vehicle collisions and low falls. ${ }^{5,7}$

Age has been long considered as a factor in the prediction of survival following injury. TRISS methodology separates age into two groups: $\leq 55$ years and $>55$ years based on MTOS figures from the early $1980 \mathrm{~s}^{5,7}$

TRISS is a score based on RTS, ISS, age and type of injury in a regression formula. Values for these factors are weighted and summed to yield TRISS which will be a value between 0 and 1 . TRISS methodology is used to calculate the probability of survival. Using available TRISS we can calculate the number of patients who would be expected to die following trauma in a group of patients. Not all patients admitted have a TRISS score. This is because all factors must be present to be calculated. TRISS has been used for evaluating the quality of trauma care by identifying patients suitable for audit analysis to determine the appropriateness and quality of individual patient care. TRISS methodology creates an isobar representing a $50 \%$ chance of survival through correlation of the ISS with the RTS. ${ }^{5}$ The outcome of each patient can be plotted relative to the isobar with survivals above the isobar considered to be 'unexpected survivals' (because they were predicted to have a probability of 
survival less than 50\%), whereas deaths below the isobar are considered 'unexpected deaths' due to their probability of survival being greater than $50 \%$ (table 2 ). ${ }^{5,7,8}$

\begin{tabular}{|l|l|l|}
\hline \multicolumn{3}{|c|}{ Table 2 - Quality of Trauma Care } \\
\hline Probability of Survival (Ps) & Outcome \\
\hline Ps $<0.5$ & Death & Expected Death \\
\hline Ps $<0.5$ & Survive & Unexpected Survival \\
\hline Ps $>0.5$ & Survive & Expected Survival \\
\hline$P s>0.5$ & Death & Unexpected Death \\
\hline
\end{tabular}

TRISS methodology is used to calculate the $Z$ statistic, which gives a comparison of outcome compared to a baseline population data established by MTOS. $Z$ statistic value outside -1.96 and +1.96 indicates that the difference between the test population and the base line population in the number of survivals or deaths is significant at $P<0.05$ level. As it is a mortality analysis, a negative value is desired. ${ }^{5,8,9}$

Because clinically unimportant deviations from the norm can still result in a $Z$ statistic that appears significant, the $\mathrm{W}$ statistic was developed to quantify the clinical significance of statistically significant $Z$ scores. $W$ is the difference between the predicted number of survivals (given by summing the predicted survival probabilities for each patient) and the actual number of survivals, divided by the total number of patients divided by 100 . This is the number of excess survivals per 100 patients, compared to the predictions. ${ }^{5,8,9}$

\begin{tabular}{|c|c|}
\hline \multicolumn{2}{|c|}{ Table 3 - The Z score and W score } \\
\hline Z score & W score \\
\hline$D-P D$ & $100(A-E)$ \\
\hline$\sqrt{P D \times P S}$ & $N$ \\
\hline $\begin{array}{c}D=\text { actual number of death } \\
\text { PD = predicted number of death } \\
\text { PS = predictive survivals }\end{array}$ & $\begin{array}{c}A=\text { the actual number of survivals } \\
E=\text { number expected } \\
N=\text { number of patients analyzed }\end{array}$ \\
\hline
\end{tabular}

RSSA is a teaching hospital with a trauma resuscitation room, equipped with 24 hour availability of operating room, and diagnostic radiology, including CT scan. ${ }^{6}$ Faculty of Medicine Brawijaya University and RSSA in collaboration with the Singapore International Foundation (SIF) has attempted to develop an integrative trauma management system in Malang, which is now called Malang Trauma Service. ${ }^{3,4,6}$ ED of RSSA Malang has claimed as the best Trauma Care Center in Malang. But its pre-hospital care is either non-existent or of poor quality. There is no pre-arrival notification or inter-hospital communication in case of trauma transfers. ${ }^{6}$

Data acquisition was a two-step process.

- All patients had their initial assessment and treatment based on Advanced Trauma and Life Support (ATLS) principles and recorded on the pre-printed trauma form. The trauma form contains information necessary to calculate probability of survival (Ps) based on TRISS methodology. ${ }^{2,8,9}$

- Step two is data entry by a surgery residence in the registry software, according to standard case criteria.,11 Trauma registry is Fox-Pro software. Registry contains demographic, anatomical and physiological scores, and process of care data. Assessment of patients' outcome was based on patients' anatomical injury and physiological state after injury, mechanism of injury, and age of the patient. Anatomical injury was coded according to AIS-90. The AIS-90 score was used to calculate ISS. ${ }^{2,10,11}$ Physiological information collected included systolic blood pressure, respiratory rate, and Glasgow Coma Scale (GCS). The coded value of physiological parameters on arrival in the emergency room is a weighted statistic and is used to yield RTS. ${ }^{2,11}$ Finally the patient's physiological score, anatomical scores, age, and type of injury (blunt or penetrating) was used to predict survival probability by TRISS analysis. ${ }^{2,8,9}$ TRISS coefficients in this study are based on AIS-90 coding 
for anatomical injury. ${ }^{2,11}$ This method offers a means of assessing a patient's probability of survival (Ps) by comparing actual survival to predict survival. ${ }^{12}$ In addition $Z$ statistic, the statistical significance of this difference, gives a comparison of outcome, compared to the baseline population data established by MTOS. ${ }^{2,6}$ The W statistic was quantitatively calculated to evaluate the difference between actual and predicted survival of patients. ${ }^{2,8,9}$

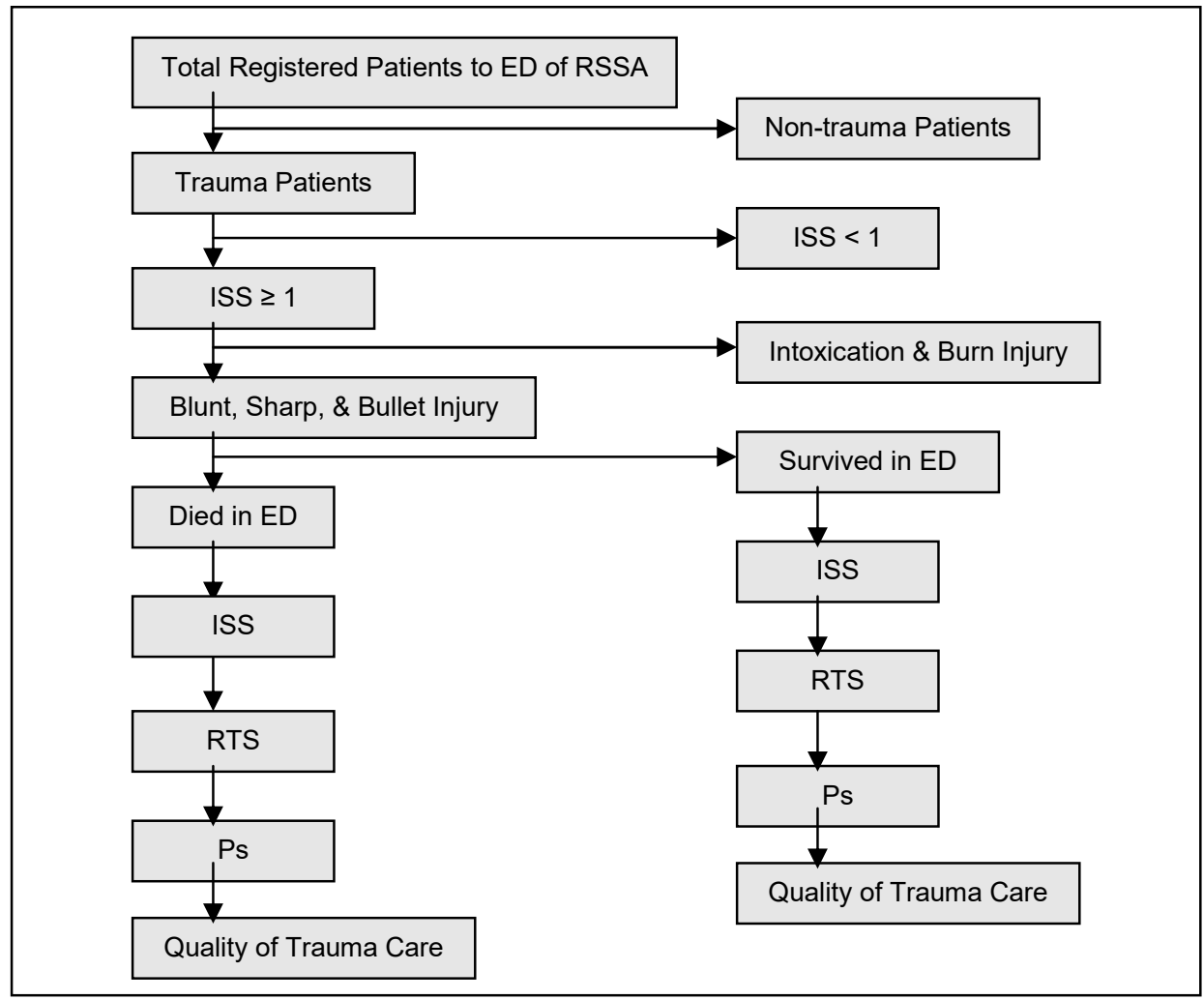

Figure 1 - Outcome of Trauma Patient Related to ISS, RTS, and TRISS

\section{RESULTS AND DISCUSSION}

From 1 May 2004 to 30 April 2005, trauma counted for $13,383(49.7 \%)$ out of 26,907 total annual attendance. There were 9758 (72.92\%) men and $3625(27.08 \%)$ women. The mortality rate of the period was $2.8 \%$. And a total 12562 patients were included in the study. Furthermore, approximately 36 persons per day admitted to the hospital were classified as having traumatic causes.

\begin{tabular}{|c|c|c|c|c|c|c|c|}
\hline \multicolumn{6}{|c|}{ Table 4 - Demographic characteristics of Inclusive Criteria Patients $(\mathrm{n}=12562$ patients) } \\
\hline \multicolumn{2}{|c|}{ Characteristic } & Transportation & Industrial & Sports & Household & Crime & Other \\
\hline Injury & Penetrating & 0.3 & 1.9 & 0.1 & 3.0 & 1.5 & 0.9 \\
\hline & Blunt & 73.8 & 1.9 & 1.4 & 7.9 & 3.7 & 3.5 \\
\hline Disposal & Discharged & 64.3 & 3.5 & 1.4 & 10.1 & 5.0 & 3.9 \\
\hline & Referral & 0.0 & 0 & 0 & 0 & 0 & 0 \\
\hline & At own risk & 7.0 & 0.2 & 0.0 & 0.6 & 0.1 & 0.3 \\
\hline & † 48 hours & 0.6 & 0 & 0 & 0.0 & 0.0 & 0.0 \\
\hline & † 48 hours & 1.1 & 0 & 0 & 0.1 & 0 & 0.1 \\
\hline Triage & P0 & 0.0 & 0.0 & 0 & 0.0 & 0.0 & 0.0 \\
\hline & P1 & 6.3 & 0.1 & 0.0 & 0.2 & 0.6 & 0.3 \\
\hline & P2 & 40.1 & 1.1 & 0.4 & 3.5 & 1.7 & 1.7 \\
\hline & P3 & 27.7 & 2.7 & 1.0 & 7.2 & 2.9 & 2.4 \\
\hline
\end{tabular}


Among causes of attendance, transportation accident $(53.8 \%$ in male and $20.3 \%$ in female) was the leading cause throughout the period (table 4). Household accidents, crime, industrial accidents, and sport injuries rank next respectively. On transportation accident, blunt injury accounted for $73.8 \%$ patients, and penetrating injury accounted for $0.3 \%$. Most of the patients were discharged from ED to ward, ICU, or home, after having their initial assessment and treatment. Almost none of the patients were referred to other hospital $(0.0 \%)$. Priority 2 seemed to be the most cases in entire modus of accident.

Injury Severity Score was available in all 12562 (100\%) patients. The mean ISS was 4.77 in the range of $1-10$, with 11379 and 97 cases of survival and non-survival, respectively. The patients' outcome according to ISS is shown in table 5.

\begin{tabular}{|c|c|c|c|c|c|c|}
\hline \multicolumn{7}{|c|}{$\begin{array}{c}\text { Table 5 - Injury Severity Score (ISS) and Patients' Outcome } \\
\text { (mean = 4,77495; standard deviation = 5,09957) }\end{array}$} \\
\hline ISS & \multicolumn{2}{c|}{ Survived } & \multicolumn{2}{c|}{ Died } & \multicolumn{3}{c|}{ Total } \\
\hline $1-10$ & 11379 & $99.15 \%$ & 97 & $00.85 \%$ & 11476 & $100 \%$ \\
\hline $10-20$ & 653 & $81.83 \%$ & 145 & $18.17 \%$ & 798 & $100 \%$ \\
\hline $20-30$ & 182 & $6740 \%$ & 88 & $32.60 \%$ & 270 & $100 \%$ \\
\hline $30-50$ & 2 & $11.11 \%$ & 16 & $88.88 \%$ & 18 & $100 \%$ \\
\hline Total & \multicolumn{2}{|c|}{$12216(97.25 \%)$} & $346(2.75 \%)$ & $12562(100 \%)$ \\
\hline
\end{tabular}

On table 6, the RTS was calculable in $12562(100 \%)$ patients. The mean RTS was 7.28 with standard deviation 1.37 . The number of survivals which mostly in the range RTS $>7$ were $9989(99.67 \%)$, while the non-survivals in that range were $33(0.33 \%)$.

\begin{tabular}{|c|c|c|c|c|c|c|}
\hline \multicolumn{7}{|c|}{ Table 6 - Revised Trauma Score (RTS) and Patients' Outcome } \\
(mean = 7,28322; standard deviation = 1,36867) \\
\hline RTS & \multicolumn{2}{c|}{ Survived } & \multicolumn{2}{c|}{ Died } & \multicolumn{3}{c|}{ Total } \\
\hline $0-1$ & 122 & $78.7 \%$ & 33 & $21.29 \%$ & 155 & $100 \%$ \\
\hline $1-2$ & 9 & $23.68 \%$ & 29 & $76.32 \%$ & 38 & $100 \%$ \\
\hline $2-3$ & 53 & $72.60 \%$ & 20 & $27.40 \%$ & 73 & $100 \%$ \\
\hline $3-4$ & 218 & $85.49 \%$ & 37 & $14.51 \%$ & 255 & $100 \%$ \\
\hline $4-5$ & 664 & $87.95 \%$ & 91 & $12.05 \%$ & 755 & $100 \%$ \\
\hline $5-6$ & 149 & $69.95 \%$ & 64 & $30.05 \%$ & 213 & $100 \%$ \\
\hline $6-7$ & 1012 & $96.29 \%$ & 39 & $3.71 \%$ & 1051 & $100 \%$ \\
\hline$>7$ & 9989 & $99.67 \%$ & 33 & $0.33 \%$ & 10022 & $100 \%$ \\
\hline Total & \multicolumn{2}{|c|}{$12216(97.25 \%)$} & $346(2.75 \%)$ & $12562(100 \%)$ \\
\hline
\end{tabular}

TRISS probability of survival could be calculated in all patients (table 7$) ; 1594(12.69 \%)$ out of 12562 patients had probability of survival of less $50 \%(P s<0.5)$. The remaining 10968 patients (87.31) had more than 50\% chance of survival (Ps>0.5). There was $1471(92.28 \%)$ unexpected survivals, while there were 10745 (97.97\%) expected survivals. The expected deaths in our study population were 123 (7.72\%), however there were $223(2.03 \%)$ unexpected deaths. Z statistic was calculated as -0.29 , with a W score of 9.93 .

\begin{tabular}{|c|c|c|c|c|c|c|}
\hline \multicolumn{7}{|c|}{$\begin{array}{l}\text { Table } 7 \text { - Trauma and Injury Severity Scoring (TRISS) and Patients' Outcome } \\
\text { (mean =0,86482; standard deviation =0,32259) }\end{array}$} \\
\hline Probability of survival (Ps) & \multicolumn{2}{|c|}{ Survived } & \multicolumn{2}{|c|}{ Died } & \multicolumn{2}{|c|}{ Total } \\
\hline \multirow[t]{2}{*}{$>0.5$} & 10745 & $97.97 \%$ & 223 & $2.03 \%$ & \multirow[t]{2}{*}{10968} & \multirow[t]{2}{*}{$100 \%$} \\
\hline & \multicolumn{2}{|c|}{ Expected survivals } & \multicolumn{2}{|c|}{ Unexpected deaths } & & \\
\hline \multirow[t]{2}{*}{$<0.5$} & 1471 & $92.28 \%$ & 123 & $7.72 \%$ & \multirow[t]{2}{*}{1594} & \multirow[t]{2}{*}{$100 \%$} \\
\hline & \multicolumn{2}{|c|}{ Unexpected survivals } & \multicolumn{2}{|c|}{ Expected deaths } & & \\
\hline \multirow[t]{2}{*}{ Total } & 12216 & $97.25 \%$ & 346 & $2.75 \%$ & \multirow{2}{*}{\multicolumn{2}{|c|}{12562}} \\
\hline & \multicolumn{2}{|c|}{ Actual number of survivals } & \multicolumn{2}{|c|}{ Actual number of deaths } & & \\
\hline
\end{tabular}

\section{DISCUSSION OF RESULTS}

Trauma scorings are applied to evaluate the effectiveness and the quality of care. TRISS methodology increases objectivity in assessing outcomes, since it has been studied 
extensively and has been widely applied in developed countries. But there is still lack of large study to judge its applicability in Indonesia. Although injury severity instruments are important, it is difficult to compare their merits. Proponents of specifics injury severity instrument claim that their instruments are effective and recommend general adoption, where as some regard them as ineffective. TRISS methodology was chosen in this study based on its reputation and ability to identify trends in the quality of trauma care. TRISS has been demonstrated to be an improvement on previous method for predicting survival in trauma patients. The patients' injury may not always be ranked correctly. The baseline norms have been framed in the United States and Canada, and their applicability to their setups, particularly in developing countries is doubtful because of less efficient emergency care. Application of TRISS methods in developing countries with western norms has not been widely reported. The actual incidence rate of injury related deaths are often higher in developing countries. $Z$ statistic, which gives a comparison of outcome, compared to a baseline population data established by the MTOS. Z statistic value -0.298 (within -1.96 and +1.96 ) indicates that the difference between the test population and the base line population in the number of survivals or deaths is not significant $(P>0.05)$. W score was developed to quantify the clinical significance of statistically significant $Z$ scores. $W$ score is the difference between the predicted number of survivals and the actual number of survivals, divided by the total number of patients divided by 100 . The actual mortality was lower than what was predicted based on TRISS norms - that is, W score of 9.93 , the number of excess survivals per 100 patients, compared to the predictions. Both $Z$ score and $W$ score reflect good performance in the management of patients with major injuries. The difference in expected and observed mortality can be attributed to good quality trauma care in RSSA setting, but it does not reflect the quality of prehospital care. ${ }^{2,6,13}$

Since 1997, Faculty of Medicine Brawijaya University and RSSA in collaboration with the Singapore International Foundation (SIF) have attempted to develop an integrative trauma management system in RSSA. This current setting up of trained full-time emergency physicians appears to be more favorable. In addition, ED of RSSA currently has a team of nurses who mainly function is Triage Officers. Well-trained nurses who function in the triage role can fairly large extend carry out the various functions that they currently perform. And the doctors can function as trained emergency physicians providing proper assessment and treatment. The trained emergency team would be handling the various types of problems and only calling upon their medical or surgical colleagues for the occasional problem that requires them immediate inputs. In addition to that, the emergency team would be able to get together various procedures to manage patients in an ambulatory setting to a greater degree and become familiar with these procedures primarily because they are working with this every day, rather on an occasional basis. Moreover, being more geared to manage patients in the emergency setting, they ability to assume emergency assessment and initiate treatment would be likely top result in more aggressive treatments so that patients would begin to get batter faster with shorter periods of morbidity, and lesser need for the hospitalization. This team would also be better attuned to the various aspects of pre-hospital care of their patients and would be able to provide the kind of medical leadership sorely needed by the community's pre-hospital Emergency Medical Service. Education of those who worked in the front of end of hospitals and building up the expertise of frontline doctors and nurses had helped tremendously in not only shortening to initial emergency care. It has also resulted in improved outcomes. ${ }^{3,4}$

\section{CONCLUSION}

Mortality per attendant proportion seems to increase although was apparently not significant; increase from $1.54 \%$ in 2000 to $2.8 \%$ in 2005 . However, no assumption can be made whether there were not any significant alterations; because of the length of the sample periods was not representative. It is only taken two year while it may take more than two years to expect any significant changes due to numerous required adjustments and adaptations. 


\section{SUGGESTIONS}

The appropriate system of Trauma Care at RSSA has not been conclusive. The Faculty of Medicine Brawijaya University and RSSA expressed that these were a need for an organized system for the comprehensive trauma care system, particularly in pre-hospital care. That they shall propose is to match each trauma care facility's or provider's resources to the needs of the injured patients, so that every patient receives optimal care from the initial recognition of the injury through return to the community.

\section{ACKNOWLEDGEMENTS}

The author would thank Dr. Edi Mustamsir, Prof. Achmad Rudijanto, Dr. Ahmad Rousdy Noor for the brain-storming sessions, and Dr. Harijanto for his help with the statistical analytic. And the author also thanks all staffs of the ED for their help with the data.

\section{REFERENCES}

1. Sukumaran, S., Henry, J.M., Beard, D., Lawrenson, R., Gordon, M.W., O'Donnell, J.J., Gray A.J. (2005). Prehospital Trauma Management: A National Study of Paramedic Activities. Emerg. Med. J., 22: p. 60-63.

2. Zafar, H., Rehmani, R., Raja, A.J., Ali, A., Ahmed, M. (2002). Registry Based Trauma Outcome: Perspective of A Developing Country. Emerg. Med. J., 19: p. 391-394.

3. Haedar, A. (2000). Evaluation of New System of Patients Management Implementation at the Emergency Department, Saiful Anwar General Hospital Malang. Presented in Asian Medical Students' Conference, Seoul - South Korea.

4. Haedar, A. (2000). Evaluasi Penerapan Sistem Pasien Trauma dengan Evaluasi Sistem Penanganan Pasien Trauma dengan menggunakan Patient Acuity Category Scale (PACS) di Instalasi Rawat Darurat RSUD Dr. Saiful Anwar Malang'. Presented in National Scientific Meeting for Medical Students, Bali - Indonesia.

5. Gabbe, B.J., Cameron, P.A., Wolfe, R. (2004). TRISS: Does It Get Better than This? Acad Emerg Med, 11(2): 181-6.

6. Noor, A.R. (2002) Evaluasi Mutu Pelayanan Trauma di Unit Gawat Darurat RSSA Malang dengan Menggunakan Metode TRISS dan Faktor-faktor yang Mempengaruhi Pelaksana dalam Melakukan Perhitungan Trauma Skor. Tugas Akhir, Fakultas Kedokteran Universitas Brawijaya.

7. Champion, H.R., Sacco, W.J., Copes, W.S. (1995). Injury Severity Scoring again. J Trauma, 38: p. 94-5.

8. Champion, H.R., Copes, W.S., Sacco, W.J. (1996). Trauma. Chapter 5 Trauma Scoring. Third Edition. Stamford: Appleton \& Lange; p. 53-67.

9. Champion, H.R., Sacco, W.J. (1989). A revision of the trauma score. J Trauma., 29: p. 623-629.

10. Tham, K.Y., Seow, E., Lau, G. (2004). Pattern of injuries in helmeted motorcyclists in Singapore. Emerg. Med. J;21; p. 478-482.

11. Boyd, C.R., Tolson, M.A., Copes, W.S. (1987). Evaluating trauma care: the TRISS method. J Trauma, 27: p. 370-378.

12. Offner, P. (2002). Trauma Scoring System. Emedicine. Retrieved from http://www.emedicine.com/med/topic3214.htm on July 2018.

13. Talwar, S., Jain, S., Porwal, R. (1999). Trauma Scoring in Developing Country. Singapore medical Journal. Singapore Med J. 40(6): p. 386-388. 